\title{
LOS LÍMITES DEL PODER CONSTITUYENTE EN EL CONSTITUCIONALISMO DEMOCRÁTICO
}

\section{Carlos Cisneros Pazmiño*}

RESUMEN: En el presente trabajo se intentará explicar y resaltar el vínculo entre el Estado constitucional y los derechos políticos del ciudadano; el que, con el ejercicio de sus derechos, directamente delimita el poder político. Así como, revisa los límites del poder constituyente y la posibilidad de que este poder absoluto caiga en error, para cuyo efecto analiza la creación del quinto poder en la Constitución ecuatoriana de 2008, expedida a la luz del constitucionalismo democrático.

PALABRAS CLAVE: poder constituyente; constitucionalismo democrático; derechos políticos; estado constitucional; constitución

\section{THE LIMITS OF CONSTITUENT POWER IN DEMOCRATIC CONSTITUCIONALISM}

ABSTRACT: This article will try to explain and highlight the link between the constitutional state and the political rights of citizens, who, in the exercise of their rights, directly limit the political power. Also, it reviews the limits of the constituent power and the possibility that this absolute power may incur in error. To this end it analyzes the creation of the fifth branch of government in the Ecuadorian Constitution of 2008, issued in light of democratic constitutionalism.

KEYWORD: constituent power; democratic constitutionalism; political rights; constitutional state; constitution

\section{Introducción}

Las teorías del contrato social explican el surgimiento a finales del siglo XVIII de un nuevo sujeto político: el ciudadano; el que asume para sí unos derechos políticos que hasta ese entonces no tenía y que, libre y voluntariamente acuerda con los otros individuos vivir en sociedad y definir los límites del accionar del Estado. Como parte esencial de ese convenio se define un régimen político en el que el individuo confiere un poder a la voluntad general, medio por el cual éste ejerce sus derechos políticos. Voluntad general esta que en tanto definidora de la Constitución se expresa a través del poder constituyente.

\footnotetext{
* Magíster en Derecho Económico y alumno del Doctorado en Derecho de la Universidad Andina Simón Bolívar, Ecuador. Máster en Administración de Empresas por la Universidad de Belgrano, Argentina. Correo electrónico: cisnerospc@yahoo.com 
Según el nuevo constitucionalismo, antecedente conceptual de la Constitución ecuatoriana de 2008 y del proceso constituyente que llevó a su expedición, el pueblo debe ejercitar su poder constituyente a través de una asamblea elegida exprofeso y del referendo que se convoque para decidir sobre el resultado de esa convención.

Dentro de los límites al ejercicio del poder constituyente, para el objeto del presente estudio se resaltan los vinculados con el ejercicio de los derechos políticos. La primera de estas limitaciones fue señalada por Schmitt (1996), quien precisó que la decisión del poder constituyente no puede reobrar contra su titular; y la segunda, postulada por Martínez Dalmau (2014), para quien el límite es la propia Constitución, puesto que el proceso constitucional es evolutivo y se desarrolla en el devenir alternado de procesos constituyentes e intermedios constituidos. Así, Schmitt, en última instancia, defiende los derechos políticos de los ciudadanos; mientras que Martínez Dalmau propugna, primordialmente, los avances en materia de derechos. Con lo cual, la limitación de Schmitt lleva implícito el reconocimiento de que el proceso constituyente puede errar; y la propuesta de Martínez Dalmau, bajo la influencia decisiva de un evolucionismo determinista en los procesos constituyentes, permite visualizar la infalibilidad del poder constituyente.

La Constitución ecuatoriana de 2008, que cumplió todos los requisitos de proceso constituyente democrático, creó el quinto poder, al que denominó “función de Transparencia y Control Social”. Este es un caso emblemático porque además del sinnúmero de críticas que en la opinión pública recibió, fue objeto de una enmienda constitucional a través de un reciente referendo, evidenciando una inconsistencia grave en su original incorporación en el texto constitucional y que puede incidir en los derechos políticos de los ciudadanos y, por tanto, afectar la infalibilidad del poder constituyente.

En el presente trabajo se intentará explicar y resaltar el vínculo entre el Estado constitucional y los derechos políticos del ciudadano, para revisar los límites del poder constituyente propuestos por Schmitt y Martínez Dalmau, y la posibilidad de que este poder ilimitado jurídicamente caiga en error, para cuyo efecto se analizará la creación del mencionado quinto poder.

\subsection{Objetivo}

CONPEDI LAW REVIEW | QUITO - EQUADOR | v. 4 | n. 2 | p. 146 - 163 | JUL - DEZ | 2018 
La finalidad del presente trabajo es definir si el poder constituyente, dentro del marco de la teoría del contrato social y los límites del poder constituyente propuestos por Schmitt y Martínez Dalmau (nuevo constitucionalismo), es infalible.

\subsection{Metodología}

La metodología que se utilizará en el trabajo es la revisión bibliográfica sobre la teoría del contrato social relacionada con el vínculo entre Estado constitucional, derechos políticos y límites del poder constituyente propuestos por Schmitt y Martínez Dalmau (nuevo constitucionalismo); que se complementará con un análisis normativo de la Constitución ecuatoriana de 2008, sobre el tema objeto de la investigación.

\section{El Estado constitucional y los derechos políticos}

El origen del Estado constitucional lo encontramos a finales del siglo XVIII cuando emergió una nueva subjetividad política: el ciudadano. En el momento en que la persona se ve a sí misma como sujeto político, con capacidad para participar en las decisiones de la sociedad y, en consecuencia, es titular de derechos políticos, surge un Estado sometido a la Constitución; y esto porque el nuevo sujeto político, con su sola presencia y más aún cuando ejerce explícitamente esas prerrogativas, determina los límites del poder del Estado. La razón de ser del constitucionalismo en esa época no es otra que la limitación. El soberano, que hasta ese entonces era una persona, libre de limitación jurídica, que da órdenes que los súbditos deben obedecer, es reemplazado por otro soberano, conformado por todos quienes integran la sociedad y que obedece las órdenes dadas también por todos ellos. (HART, 1963)

Las teorías del contrato social, en tanto compromiso previo mutuo entre todos los integrantes de una sociedad para alcanzar propósitos comunes y los intereses de cada individuo, (FREEMAN, 2016) explican el surgimiento del nuevo sujeto político.

La participación del ciudadano como persona libre y autónoma y, por tanto, con capacidad política y jurídica para obligarse, es decir, en tanto titular de derechos políticos, es el postulado de las teorías contractualistas que permite que el individuo se adhiera al convenio 
social sin la determinación de poder externo al ser humano y sin coacción alguna, tan sólo en procura de una contraprestación del resto de miembros de la sociedad que beneficie a todos.

Para Hobbes (2011), los hombres requieren de un poder común que los mantenga atemorizados y que dirija sus acciones al logro del bien común. El único modo de erigir un poder común que pueda defenderlos de la invasión de los extraños y de las injurias entre ellos mismos, proporcionándoles seguridad, es el de que cada uno confiera libre y voluntariamente su poder individual a un solo hombre o a una asamblea de hombres que, mediante una pluralidad de votos, puedan reducir las voluntades individuales a una sola voluntad. ${ }^{1}$

Según Locke, el pacto social es un acuerdo suscrito entre sí por las personas como individuos con la finalidad de unirse en una sola sociedad que será gobernada por un régimen político, que la mayoría de la sociedad decida que es el apropiado. (RAWLS, 2017) El contrato social de Locke es un acuerdo para formar y unirse a un cuerpo político, al cual se le otorga la responsabilidad de crear una constitución política y un gobierno que ejerza el poder político que se le ha conferido en beneficio del pueblo. (FREEMAN, 2016)

Por su parte, Rousseau (1957) considera que el contrato social es la asociación que protege con toda la fuerza común a la persona y los bienes de cada asociado, y por la cual, uniéndose cada uno a todos, sólo se obedece a sí mismo y permanece tan libre como antes. En virtud del contrato social, el soberano está formado por los particulares que lo componen y, por ende, su interés es el interés de todos, representado en la idea del bien común, que no es ni puede ser contrario al de sus miembros. El contrato social de Rousseau es un acuerdo desde el punto de vista de ciudadanos libres e iguales, en el que cada uno delibera y trata de expresar la voluntad general de esos ciudadanos. (FREEMAN, 2016)

Al igual que Hobbes, Locke y Rousseau, Rawls $(2002,2008)$ parte de considerar que los ciudadanos son seres morales; lo que no sólo quiere decir que tienen la capacidad de tener unas ideas del bien y de la justicia y, por ende, el deseo de actuar según la exigencia de esta concepción, sino que también pueden apreciar el comportamiento de las instituciones políticas y del resto de los ciudadanos; por lo que, únicamente si los ciudadanos tienen una "razonable seguridad" de que las instituciones políticas son justas y que los demás ciudadanos cumplirán

${ }^{1}$ Coinciden con esta interpretación de Hobbes tanto Rawls (2017) como Freeman (2016). CONPEDI LAW REVIEW | QUITO - EQUADOR | v. 4 | n. 2 | p. 146 - 163 | JUL - DEZ | 2018 
su parte, estarán dispuestos a acatar el contrato social. La confianza de los ciudadanos en el convenio cooperativo hace que éste se cumpla voluntariamente.

Sin embargo, las personas libres e iguales tienen diferentes valores y creencias, y no hay una autoridad moral, religiosa o filosófica comúnmente aceptada a la que pudiera consultarse para dirimir los desacuerdos. Por esto, según Rawls, la única manera de que los principios de la justicia sean aceptables para todos es mediante un acuerdo social basado en la "posición original"; (FREEMAN, 2016) es decir, en un procedimiento equitativo que anule los efectos de las contingencias específicas que ponen a los hombres en situaciones desiguales. Para el efecto, Rawls (2015) utiliza el concepto de "velo de ignorancia", que es una condición de los ciudadanos por la que no saben cómo en la discusión política las diversas alternativas afectarán sus propios casos particulares, viéndose así obligados a evaluar los principios únicamente sobre la base de consideraciones generales. De esta manera, el contrato social se interpreta bajo una misma «razón pública», que se conforma por los principios e ideales que la sociedad tiene acerca de la política. En esencia, Rawls propugna que esquema de cooperación social funciona cuando sus reglas básicas se obedecen voluntariamente. Para lo cual es necesaria la confianza en las instituciones políticas, lo que a su vez se consigue con el compromiso y comportamiento de todos los ciudadanos, que han ejercicio sus derechos políticos en condiciones de igualdad y en función de la «razón pública», es decir, bajo unos mismos principios e ideales.

Como se puede observar, en las doctrinas contractualistas el titular de los derechos políticos es el individuo, el que libre y voluntariamente acuerda con los otros individuos -con los mismos derechos políticos-, vivir en sociedad; y, como parte esencial de ese convenio, define el régimen político que conducirá esa sociedad hacia la consecución del bien común. En ese régimen político es imprescindible que el individuo confiera un poder y autorice su ejercicio a alguien diferente a él: la «sola voluntad» (Hobbes) o «voluntad general» (Rousseau), que es la que recoge la voluntad individual y le presta un mérito político y jurídico efectivos, en función de la «razón pública» (Rawls). Sólo por medio de la voluntad colectiva el ciudadano ejerce sus derechos políticos.

La voluntad colectiva y los derechos políticos de los individuos son una sola e indivisible cosa, cual hoja de papel, con su anverso y su reverso; pues, la democracia es la 
única manera cómo ese individuo, revestido de poder político $\mathrm{y}$, consecuentemente, de derechos políticos, puede adoptar legítimamente las decisiones colectivas, dirigidas y obligatorias para todos los miembros de la comunidad y para el Estado.

Ya el abate Sieyés (1985), en la época revolucionaria francesa, decía que sólo la voluntad de la nación podía decidir por sí misma y, para él, la nación era el conjunto de ciudadanos que poseen idénticos derechos políticos.

Estas ideas fueron concretadas en Europa a finales del siglo XVIII a través de fórmulas políticas y jurídicas. El pilar normativo que se levantó fue el derecho constitucional, conformado por un cúmulo de garantías individuales y limitaciones a la actuación del Estado; (RESTREPO, 1956) derecho este que pasa a cumplir una función decisiva para el individuo: le protege de unos individuos frente a otros, del individuo ante el colectivo, de todos y cada uno frente al más peligroso depredador: el Estado mismo. (DEL ÁGUILA, 1995)

Surge así el Estado de derecho, concebido como la garantía política de que la actuación del Estado está determinada por la Constitución y la ley, instituidos legítimamente por el ciudadano en ejercicio de sus derechos políticos. El Estado está subordinado a la voluntad política y, a unísono, a los derechos políticos de los ciudadanos. García y Ramón dicen:

La fuente del Derecho no está en ninguna instancia supuestamente trascendental a la comunidad, sino en ésta misma, en su voluntad general; y, a la vez, sólo hay una forma legítima de expresión de esta voluntad, la Ley general [...] que ha de determinar todos y cada uno de los actos singulares del poder. (GARCÍA; RAMÓN, 1997, p. 424)

\section{El poder constituyente y sus límites}

Como señalamos con antelación, el titular de los derechos políticos es el individuo, el que libre y voluntariamente acuerda con los otros individuos vivir en sociedad; y, como parte esencial de ese convenio, define el régimen político que conducirá esa sociedad hacia el bien común; régimen político en el cual el individuo confiere el poder y autoriza su ejercicio a una «sola voluntad» o «voluntad general», que es la que recoge la voluntad individual y le presta 
un mérito político y jurídico efectivo. Esta voluntad general, cuando se trata de expedir una Constitución, se expresa como poder constituyente ${ }^{2}$; y que, en los regímenes democráticos, viene a ser el único con la potestad para expedir la norma suprema. ${ }^{3}$

De acuerdo al nuevo constitucionalismo, el pueblo, concebido como el conjunto de ciudadanos de una determinada comunidad política, debe ejercitar su poder constituyente a través de una asamblea o convención elegida exprofeso, y el resultado de su tarea debe ser refrendado directamente por los ciudadanos; con lo cual se consigue que la Constitución, como marco jurídico-político, sea establecida directamente por los ciudadanos para limitar el ejercicio del poder político. (VICIANO, 2001) Así, sólo el pueblo puede sentirse progenitor de la Constitución, por la genuina dinámica participativa y legitimadora que acompaña a los procesos constituyentes. (VICIANO; MARTÍNEZ DALMAU, 2010)

A pesar de que el poder constituyente se caracteriza por ser originario, ilimitado, soberano y legitimador, ${ }^{4}$ está limitado en su ejercicio. Sagüés (2012), por ejemplo, los resume en los límites fácticos, principalmente históricos y sociales; los normativos, relacionados con las obligaciones del Estado en el derecho internacional y respecto de los derechos humanos; y los axiológicos, que recogen principios político-jurídicos que limitan la potestad del poder constituyente, plasmados en postulados de derecho natural, como la dignidad del hombre.

Dentro de los límites al poder constituyente, para el objeto del presente estudio se resaltan dos, que tienen una relación directa con el ejercicio de los derechos políticos, en tanto

\footnotetext{
${ }^{2}$ Por ejemplo, Schmitt (1996) consideraba que el poder constituyente es la voluntad política cuya fuerza o autoridad es capaz de adoptar la concreta decisión de conjunto sobre modo y forma de la propia existencia política, determinando así la existencia de la unidad política como un todo, decisión de la que se deriva la validez de toda ulterior regulación legal-constitucional. Rawls (2017) dirá que es el poder de determinar la forma de gobierno, la constitución misma.

${ }_{3}^{3}$ Ferrajoli (2011), por ejemplo, señala que el poder constituyente en los sistemas democráticos se identifica con la soberanía popular, es decir, con el conjunto de libertades pre políticas y pre jurídicas de todos los consociados, cuyo ejercicio da vida al pactum associationis.

${ }^{4}$ Para Ferrajoli (2011, p. 805-6): "Se trata de un poder por completo singular. Es en primer lugar un poder no positivo, dado que no es producto de ningún acto, y por tanto originario. En segundo lugar, no es un poder regulado por normas, al no ser él mismo ni una norma, ni una situación predispuesta por una norma, sino un poder desregulado, que por tanto no puede calificarse como legítimo o ilegítimo.” Para Martínez Dalmau (2014, p. 72): “... poder constituyente (ilimitado y soberano, plenamente legitimador) es crear poder constituido (limitado y dependiente, plenamente legitimado)" Para Sagüés (2012, p. 56): "Tradicionalmente se define al poder constituyente originario como autónomo, incondicionado, trascendente con relación al orden jurídico positivo (Sánchez Agesta). Otros le atribuyen la 'soberanía originaria, extraordinaria, suprema y directa' (Sánchez Viamonte), con ribetes de poder político más que jurídico." Para De Vega (2011, p. 27-8): "De la calificación del poder constituyente como poder soberano e ilimitado [...] el poder constituyente, en cuanto poder pre-jurídico, como res facti, non juris, no sólo es ilimitado en los contenidos de su voluntad, sino en las propias formas de su ejercicio."
} 
estos son el antecedente político y jurídico que informa ese poder constituyente. La primera de estas limitaciones fue señalada por Schmitt, quien precisó que la decisión del poder constituyente no puede reobrar contra su titular; y la segunda, postulada por Martínez Dalmau, para quien el límite es la propia Constitución, puesto que el proceso constitucional es evolutivo y se desarrolla en el devenir alternado de procesos constituyentes e intermedios constituidos. A continuación, revisaremos cada una de estas limitaciones.

\subsection{La limitación por la afectación al titular del poder constituyente}

La primera limitación al poder constituyente la expuso Schmitt (1996), quien precisó que la decisión política implicada en la Constitución no puede reobrar contra su sujeto, ni destruir su existencia política; resaltando que, al lado y por encima de la Constitución, sigue subsistiendo la voluntad política que conforma el poder constituyente.

Schmitt (1996) consideraba que el poder constituyente es la voluntad política cuya fuerza o autoridad es capaz de adoptar la concreta decisión de conjunto sobre modo y forma de la propia existencia política, determinando así la existencia de la unidad política como un todo, decisión de la que se deriva la validez de toda ulterior regulación legal-constitucional. Para él, el titular del poder constituyente es la comunidad política y, por tanto, no se podría dar un accionar suyo en contra de ella.

En este orden de ideas, el poder constituyente no podría adoptar una decisión que vaya en contra de él mismo, es decir, de la voluntad general que le informa o, más precisamente y utilizando la terminología de Rawls, en desatención de la razón pública, que refleja los principios e ideales que la sociedad tiene acerca de la política. Y esto porque la voluntad general, imbuida de esos principios e ideales, es la que determina el poder constituyente, el cual es sólo una expresión de esa voluntad general. El poder constituyente no es un poder extraño a la voluntad general; como lo señalamos con antelación, es únicamente una explicitación de esa voluntad general cuando se trata de expedir la Constitución que regirá una comunidad política.

Pero hay más. Al irse contra la voluntad general y su razón pública, el poder constituyente viola los derechos políticos de los ciudadanos; pues estos derechos políticos son 
la justificación política y jurídica de su existencia, de su actuación y de sus resultados. El poder constituyente conformado en asamblea no es titular de derecho político alguno; son los ciudadanos los únicos titulares de los derechos políticos y, como tales, los que eligen o son elegidos, como representantes de otros ciudadanos, para integrar esa asamblea, con el único mandato de cumplir la voluntad general, inspirada por la razón pública. Y, si a esto sumamos que, desoyendo el origen y esencia del constitucionalismo, el poder constituyente en lugar de limitar el poder político facilita sus excesos, como por ejemplo cuando reduce o elimina los controles políticos al accionar del Estado, afecta directamente los derechos políticos de los ciudadanos, con los cuales y para los cuales se instituyó ese Estado sujeto a la Constitución.

El Estado constitucional, como lo indicamos previamente, emergió con el surgimiento de la nueva subjetividad política: el ciudadano; es decir, cuando la persona se ve a sí mismo como sujeto político, con capacidad para participar en las decisiones de la sociedad y, en consecuencia, es titular de derechos políticos. La persona es un sujeto de derechos políticos y, como tal, irradia un aura que delimita un espacio político y jurídico vedado al Estado. La sola presencia de la persona define una frontera con el Estado, que se muestra subyacente en la convivencia del ciudadano con ese Estado y que aparece en los ideales y principios de la razón pública. El ejercicio de los derechos políticos por parte del ciudadano es, pues, sólo la explicitación de ese límite; es el expresar, dejar sentado, hasta dónde puede el Estado actuar. Entonces, le es prohibido a la asamblea constituyente intentar borrar las líneas que reflejan esa frontera implícita porque al hacerlo contradeciría la razón pública que informa su voluntad general.

Al existir esta limitación, Schmitt reconoce -aunque no tan expresamente- que el proceso constituyente puede errar. Una asamblea constituyente puede desoír la voluntad general y su razón pública y, atentando contra los derechos políticos de los ciudadanos, ir en contra del titular de ese poder constituyente. Y no lo reconoce tan claramente porque imputa esta responsabilidad al proceso y sus gestores, los políticos, quienes eran los llamados a reconocer la voluntad constituyente, antes que al pueblo mismo. Schmitt (1996) hace alusión a la "debilidad" del pueblo al decidir sobre las cuestiones fundamentales de su forma política y su organización, "sin estar formado u organizado él mismo, por lo que pueden desconocerse, interpretarse mal o falsearse con facilidad sus manifestaciones de voluntad", observando negativamente que la voluntad constituyente del pueblo se manifiesta siempre y 
simplemente en un "sí o no fundamental". En todo caso, Schmitt se resistió a decir con toda claridad, como efecto él mismo creía, que el propio poder constituyente podía equivocarse.

\subsection{La limitación por la afectación a la propia Constitución}

El segundo límite del poder constituyente lo defiende Martínez Dalmau (2014). Él indica que esa limitación se encuentra en la propia Constitución. Argumenta en favor de esta tesis que el concepto de democracia constitucional pone el énfasis en el constitucionalismo como límite y, por lo tanto, control al poder; y aparta la posibilidad de un poder constituyente absoluto; puesto que, cualquier poder absoluto por sí mismo es contrario a la existencia de los derechos en tanto éstos son ámbitos exentos de poder ajeno.

Martínez Dalmau (2014) parte de reconocer la evolución de los procesos constitucionales, entre intervalos de procesos constituyentes e intermedios constituidos, resaltando la cualidad emancipadora y evolutiva del constitucionalismo democrático, en un sentido progresista.

Si aceptamos la idea de que el constitucionalismo es evolutivo, cobra plena validez el límite sugerido por Martínez Dalmau, ya que siempre los resultados de los procesos constituyentes serán válidos, bajo la única condición de que los resultados de los procesos ulteriores sean siempre incrementales en reconocimiento de derechos $\mathrm{y}$, a la vez y en correspondencia, en mayor limitación al poder político. La intención es, sin lugar a duda, proteger los logros alcanzados en el proceso constituyente anterior. De esta manera, todo lo que se haga por medio de los procesos constituyentes será válido; claro, siempre y cuando el desarrollo de los procesos constituyentes se haga bajo los parámetros definidos por el constitucionalismo democrático. Así, y tal vez sin quererlo, se termina reconociendo la infalibilidad del poder constituyente.

Además de ser muy discutible el carácter evolutivo sin lugar a error de cualquier obra humana y, por ende, de los procesos constituyentes, esta cualidad genera una presión continua en pro de más avances en materia de derechos, lo que en sí es muy positivo, pero que en ciertos casos puede producir un conflicto de derechos y aún un retroceso en alguno de ellos. 
Un ejemplo de este menoscabo y que se tratará con mayor profundidad en el siguiente apartado de este trabajo, se dio en la asamblea constituyente ecuatoriana de 2008, entre los derechos políticos propiamente dichos y los derechos de participación ciudadana, que se encuentran vinculados a los temas de transparencia y rendición de cuentas. La intención de la asamblea fue incrementar estos derechos de participación y lo hizo reduciendo los derechos políticos, al eliminar en la Constitución de 2008 una atribución que siempre perteneció al Parlamento, que es la de designar a las máximas autoridades del Estado, especialmente con funciones de control, y traspasar esta facultad al quinto poder, un nuevo organismo no elegido democráticamente.

Para finalizar esta parte del trabajo, es necesario recordar que los teóricos contractualistas no reconocían la posibilidad de errar del poder constituyente. Se creía que como poder absoluto no se equivoca. Para Rousseau (1957, p. 65, 84), por ejemplo, el poder soberano no tiene ni puede tener interés contrario al de los particulares que lo componen y, por tanto, es imposible que quiera o pueda perjudicar a uno de sus miembros. "El soberano, por el simple hecho de ser, es siempre todo lo que debe ser", y por ello es infalible. En esta línea de pensamiento, un acto del poder soberano es un "convenio legítimo, porque tiene por base el contrato social; equitativo, porque es común a todos; útil, porque no puede tener otro objeto que el bien general, y sólido, porque tiene por fiador la fuerza pública y el poder supremo." La voluntad general es siempre recta y tiende invariablemente al bien público.

Rawls (2017, p. 32-3; 2008, p. 164-5, 204) disiente con sus antecesores sobre la categoría absoluta de la voluntad general, al definir un cúmulo de condiciones que, si se cumplen, se traducen en la razonable seguridad en el cumplimiento del contrato social. Rawls utiliza dos conceptos: la "concepción pública de la justicia" y la "estructura básica" de la sociedad. La primera, proporciona un punto de vista mutuamente reconocido por todos los ciudadanos desde el cual éstos pueden arbitrar sus exigencias de derecho político a las instituciones. La segunda, es el modo en que las principales instituciones políticas encajan en un sistema de cooperación social. Esta "estructura básica" es el marco social de trasfondo en cuyo seno tienen lugar las actividades de los individuos y asegura lo que denomina la justicia de trasfondo. La "concepción pública de la justicia" y la "estructura básica" de la sociedad reflejan la «razón pública», que -como hemos dicho anteriormente- tiene por contenido los principios e ideales que expresa la concepción de la sociedad acerca de la política y que 
permite a los ciudadanos advertir si sus instituciones son justas o no, y por tanto, si una expresión del poder constituyente es acertada o no.

En el punto siguiente se revisará el caso de la creación del quinto poder en la Constitución ecuatoriana de 2008, y que evidencia una inconsistencia grave que puede incidir en los derechos políticos de los ciudadanos $\mathrm{y}$, por tanto, afecta la infalibilidad del poder constituyente.

\section{El caso del quinto poder}

La Constitución ecuatoriana de 2008, entre las varias innovaciones que incorporó, instituyó la función de "Transparencia y Control Social", asimilándola a los poderes tradicionales: ejecutivo, legislativo y judicial, a los que la norma suprema añade también lo electoral. En total, los poderes llegan a ser cinco. ${ }^{5}$

El Consejo de Participación Ciudadana y Control Social, que viene a ser la parte esencial de la novel función, tiene la misión de promover la participación ciudadana y el control social en los asuntos de interés público, además de designar al Procurador General del Estado y Superintendentes, de las ternas propuestas por el Presidente de la República; así como designar por concurso de méritos y oposición al Defensor del Pueblo, Defensor Público, Fiscal y Contralor Generales del Estado, y a los miembros del Consejo Nacional Electoral, Tribunal Contencioso Electoral y Consejo de la Judicatura. (Constitución, Art. 207, 208)

El Consejo se integra por siete consejeros principales y siete suplentes, cuya "selección" se realiza de entre los postulantes que propongan las organizaciones sociales y la ciudadanía. El Consejo Nacional Electoral conduce el concurso público de oposición y méritos correspondiente, con postulación, veeduría y derecho a impugnación ciudadana. (Constitución, Art. 207, 208)

Los concursos de méritos y oposición para la designación de autoridades, por su parte, son gestionados por las comisiones ciudadanas de selección, organizadas por el Consejo e

\footnotetext{
${ }^{5}$ Constitución de la República, Art. 225: "El sector público comprende: 1. Los organismos y dependencias de las funciones Ejecutiva, Legislativa, Judicial, Electoral y de Transparencia y Control Social." CONPEDI LAW REVIEW | QUITO - EQUADOR | v. 4 | n. 2 | p. 146 - 163 | JUL - DEZ | 2018 
integradas por un delegado de cada función del Estado e igual número de representantes por las organizaciones sociales y la ciudadanía, escogidos en sorteo público de entre quienes se postulen y cumplan con los requisitos que determinen la ley y el propio Consejo, el que debe escoger a quien obtenga la mejor puntuación en el respectivo concurso e informar a la Asamblea Nacional para la posesión respectiva. (Constitución, Art. 208 No. 9, 209, 210) Con esto, la atribución de la función Legislativa se redujo a un simple formalismo: la posesión de las autoridades designadas por el Consejo de Participación Ciudadana y Control Social. ${ }^{6}$

La innovación de la Constitución de 2008 rompió con una larga tradición constitucional, respetada inclusive desde el regreso a la democracia en 1978, que confería al Congreso Nacional la potestad de nombrar a las máximas autoridades de las instituciones del Estado, y que en la Carta Suprema de 1998 incluía al Procurador General del Estado, Ministro Fiscal General, Contralor General del Estado, Defensor del Pueblo, superintendentes, vocales del Tribunal Constitucional y Tribunal Supremo Electoral y miembros del directorio del Banco Central; debiendo resaltarse que la designación del juez de cuentas requería una mayoría calificada: las dos terceras partes de los diputados. ${ }^{7}$

Esta innovación, a pesar de que seguramente tuvo una intención válida, en el sentido de incrementar los derechos de participación ciudadana, que se encuentran vinculados a los temas de transparencia y rendición de cuentas; implicó una reducción de los derechos políticos de los ciudadanos, conforme lo veremos a continuación.

\footnotetext{
${ }^{6}$ Constitución de la República, Art. 120: "La Asamblea Nacional tendrá las siguientes atribuciones y deberes, además de las que determine la ley: [...] 11. Posesionar a la máxima autoridad de la Procuraduría General del Estado, Contraloría General del Estado, Fiscalía General del Estado, Defensoría del Pueblo, Defensoría Pública, Superintendencias, y a los miembros del Consejo Nacional Electoral, del Consejo de la Judicatura y del Consejo de Participación Ciudadana y Control Social."

${ }^{7}$ Por ejemplo, la Constitución de 1978, codificada en 1984 (Registro Oficial No. 763 de 12 de junio de 1984), Art. 59: "El Congreso Nacional se reúne en pleno, sin necesidad de convocatoria, en Quito, el 10 de agosto de cada año y sesiona durante sesenta días improrrogables, para conocer exclusivamente de los siguientes asuntos: [...] j) Nombrar al Contralor General, al Procurador General, al Ministro Fiscal y a los Superintendentes de bancos y de Compañías, de las ternas que le sean enviadas por el Presidente de la República y removerlos, si fuere del caso;"; y la Constitución de 1998 (Registro Oficial No. 1 de 11 de agosto de 1998), Art. 130: "El Congreso Nacional tendrá los siguientes deberes y atribuciones: 11. Nombrar al Procurador General del Estado, al Ministro Fiscal General, al Defensor del Pueblo, a los superintendentes; a los vocales del Tribunal Constitucional y Tribunal Supremo Electoral y a los miembros del directorio del Banco Central; conocer sus excusas o renuncias, y designar a sus reemplazos. [...] 12. Elegir por mayoría de las dos terceras partes de sus integrantes la terna para la designación del Contralor General del Estado. Se procederá de la misma manera para reemplazarlo, en caso de falta definitiva."
} 
Parte esencial de los derechos políticos de los ciudadanos es la de elegir y ser elegidos a cargos de elección popular, a través del voto universal, igual, directo, secreto y escrutado

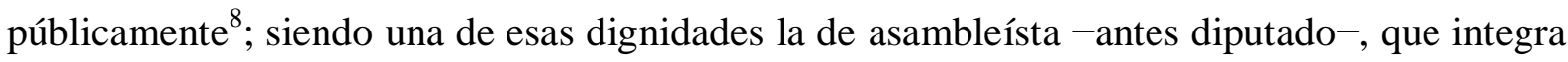
la Asamblea Nacional -antes Congreso Nacional-, organismo que a su vez ejerce la función Legislativa y que viene a constituir el principal espacio democrático y, por ende, el límite por antonomasia al ejercicio del poder por el Ejecutivo. De ahí que, la eliminación de una facultad del Parlamento puede conllevar la limitación de los derechos políticos de un ciudadano, porque este ciudadano - ni ningún otro ciudadano- ya no podrá ejercer por sí mismo o por su representante, a quien le confirió su voto, la potestad que se le arrebata.

En el caso de la innovación de la Constitución de 2008 (Art. 61 No. 5), se eliminó la atribución de la Asamblea Nacional de nombrar a las máximas autoridades del Estado, que son principalmente de control, y se transfirió esta facultad a un organismo burocrático cuyos miembros no son elegidos por el pueblo sino por la autoridad electoral a través de un supuesto concurso de méritos y oposición. De esta manera, los ciudadanos perdieron el derecho de designar autoridades de control y, con ello, afectó directamente el derecho político de controlar al poder político y que, en el mismo texto constitucional se reconoce como el de fiscalizar los actos del poder público.

Por ejemplo, la misma Constitución de 2008 (Art. , 211, 212, 233) determina que ninguna servidora ni servidor público estará exento de responsabilidades por los actos realizados en el ejercicio de sus funciones o por omisiones, y serán responsable administrativa, civil y penalmente por el manejo y administración de fondos, bienes o recursos públicos; y que la Contraloría General del Estado es la encargada del control de la utilización de los recursos estatales, así como de determinar responsabilidades administrativas y civiles culposas e indicios de responsabilidad penal. En la Constitución del 1998 (Art. 130 No. 12) la designación de la máxima autoridad de la Contraloría correspondía al Congreso Nacional y con mayoría calificada: las dos terceras partes de los diputados; por lo que, es evidente que al eliminarse esta atribución en la Constitución de 2008 y trasladarla a un organismo sin representación democrática, se afectó el derecho político de los ciudadanos al

\footnotetext{
${ }^{8}$ Por ejemplo, Constitución de 1978, codificada en 1984, Arts. 32 y 33; Constitución de 1998, Arts. 26 y 27; y Constitución de 2008, Arts. 61 y 62. 
control del poder político. A más de que, al ser designado el juez de cuentas por un organismo burocrático, se diluyó el límite que comporta la Constitución en un Estado constitucional.

En adición, son de resaltar otras consecuencias determinantes de la modificación introducida por la Constitución de 2008: 1) La participación ciudadana y el control social, contradictoriamente a su esencia, se estatizaron y pasaron a depender de la organización y decisiones del Consejo de Participación Ciudadana y Control Social; 2) La nueva burocracia de la participación ciudadana, como todo ente estatal, fue capturada por el Gobierno de turno y de una manera totalitaria, sin admitir disidencia alguna; y, 3) Esa captura del Consejo, en la práctica, conllevó a una falta absoluta de confianza por parte de los ciudadanos y la sociedad civil tanto en los instrumentos como en los resultados del proceso de designación de las máximas autoridades; los mal llamados concursos de méritos y oposición y las decisiones del Consejo fueron poco creíbles.

Como respuesta al descrédito del Consejo de Participación Ciudadana y Control Social, recién electo el Presidente de la República convocó a los ecuatorianos, ecuatorianas y extranjeros residentes en el Ecuador con derecho a sufragio, a referéndum y consulta popular, que se efectuaron el día domingo 04 de febrero de 2018, y en las que -entre otras propuestasse preguntó a la ciudadanía:

¿Está usted de acuerdo con enmendar la Constitución de la República del Ecuador para reestructurar al Consejo de Participación Ciudadana y Control Social, así como dar por terminado el período constitucional de sus actuales miembros, y que el Consejo que asuma transitoriamente sus funciones tenga la potestad de evaluar el desempeño de las autoridades cuya designación le corresponde, pudiendo, de ser el caso, anticipar la terminación de sus períodos $[\ldots]$ ?. ${ }^{9}$

El 08 de febrero de 2018, el Consejo Nacional Electoral proclamó los resultados definitivos de la consulta popular y referéndum, habiendo obtenido la opción "SI" de la pregunta referente a la reestructuración del Consejo de Participación Ciudadana y Control

\footnotetext{
${ }^{9}$ Decretos Ejecutivos No. 229 y 230, los dos de 29 de noviembre de 2017. Con Resolución No. PLE-CNE-3-112-2017 de 01 de diciembre de 2017 (Segundo Suplemento del Registro Oficial No. 135 de 7 de diciembre de 2017), el Consejo Nacional Electoral aprobó dicha Convocatoria; y con Resolución No. PLE-CNE-4-1-12-2017 de 1 de diciembre de 2017, declaró el inicio del período electoral respectivo.
} 
Social, la cantidad de 5'983.061 votos que representaba el 63,08\% del total de los votos válidos de las y los sufragantes que constaban en el Registro Electoral. ${ }^{10}$

Si bien esta enmienda a la Constitución reflejó la captura del quinto poder, no fue al fondo del asunto y no se consideró que, más allá de las circunstancias del momento, fue un error el haber conferido una atribución propia de la función Legislativa a un ente burocrático no elegido democráticamente, desnaturalizando por completo la designación de las máximas autoridades de las principales instituciones del Estado, lo que hizo que se suavizara la limitación al poder político que en esencia es el original y principal objetivo de la Constitución y se menoscabaran los derechos políticos de los ciudadanos, ya contemplados en las Constituciones precedentes, incluida la de 1998.

\section{Una necesaria conclusión}

La creación del quinto poder por la Constitución de 2008 menoscabó los derechos políticos de los ciudadanos y redujo los límites al poder político pues eliminó de las atribuciones de la Asamblea Nacional, principal espacio democrático y, por tanto, el límite por antonomasia al ejercicio del poder por el Ejecutivo, la facultad de designar a las autoridades que ejercerán el control del poder, y traspasó esa potestad a un ente burocrático no elegido democráticamente.

Schmitt tenía en razón al señalar que la decisión política implicada en la Constitución no puede reobrar contra la voluntad política. Tampoco puede estar en oposición a los principios e ideales que la sociedad tiene acerca de la política. El poder constituyente no es un poder extraño a la voluntad general y su razón pública; es únicamente una explicitación de esa voluntad para expedir la Constitución que regirá una comunidad política. Por lo que, al irse contra la voluntad general y su razón pública, el poder constituyente viola los derechos políticos de los ciudadanos; más aún si, desoyendo el origen del constitucionalismo, el poder constituyente en lugar de limitar el poder político facilita sus excesos, al reducir los controles al accionar del Estado.

\footnotetext{
${ }^{10}$ Resolución No. PLE-CNE-1-8-2-2018-R de 08 de febrero de 2018 (Suplemento del Registro Oficial No. 180 de 14 de febrero de 2018). 
Martínez Dalmau también está en lo justo cuando resalta el constitucionalismo como límite y, por lo tanto, aparta la posibilidad de un poder constituyente absoluto, con lo que el límite de ese poder está en los avances en derechos alcanzados en el proceso constituyente anterior o, en la Constitución vigente, porque esos avances y, en sí, los derechos reconocidos en un texto constitucional, especialmente si es consecuencia de un proceso constituyente democrático, son el reflejo de la voluntad política y razón pública en un momento histórico determinado; y en este sentido, sólo en este sentido, cabe entender el proceso constituyente como una evolución, un progreso.

Lo que no se puede aceptar es que, per se, sólo por ser el poder constituyente o, por desarrollarse un proceso constituyente democrático, siempre y en todos los aspectos va a existir un resultado positivo. La obra humana es falible por esencia y el poder constituyente no puede ser la excepción. El caso de la innovación de la Constitución ecuatoriana de 2008 evidencia que el poder constituyente sí puede errar.

Como diría Schmitt, parece que en el caso de la norma constitucional que regula el Consejo de Participación Ciudadana y Control Social y en la enmienda que permite su reestructuración, se interpretó mal la voluntad popular.

\section{Bibliografía}

DE VEGA, P. La reforma constitucional y la problemática del poder constituyente. Madrid: Tecnos, 2011.

DEL ÁGUILA, R. El centauro transmoderno: liberalismo y democracia en la democracia liberal. En Fernando Vallespín (Comp.). Historia de la Teoría Política, t. VI. Madrid: Alianza Editorial, 1995.

DEL VECCHIO, G.; RECASÉNS SICHES, L. Filosofía del Derecho, t. II. México: Unión Tipográfica Editorial Hispano-americana, 1946.

FERRAJOLI, L. Principia iuris. Madrid: Trotta S.A., 2011.

FREEMAN, S. Rawls. México: Fondo de Cultura Económica, 2016.

GARCÍA DE ENTERRÍA, E. La constitución como norma y el tribunal constitucional. Madrid: Civitas S.A., 1985. ; RAMÓN, T. Curso de Derecho Administrativo, t. I. Madrid: Civitas S.A., 1997. 
GARGARELLA, R. Historia Constitucional. En Susana Albanese et. al., Derecho Constitucional. Buenos Aires: Editorial Universidad, 2004.

HABERMAS, J. Facticidad y validez. Madrid: Trotta S.A., 2010.

HART, H. L. A. El concepto de derecho. Buenos Aires: Abeledo-Perrot S.A., 1963.

HOBBES, T. Leviatán. Madrid: Alianza Editorial, 2011.

MARTÍNEZ DALMAU, R. El debate sobre la naturaleza del poder constituyente: elementos para una teoría de la constitución democrática. En: Teoría y práctica del poder constituyente. Valencia: Tirant lo Blanch, 2014.

RAWLS, J. Teoría de la justicia. México: Fondo de Cultura Económica, 2015.

La justicia como equidad. Madrid: Paidós, 2002.

Liberalismo político. México: Fondo de Cultura Económica, 2008.

. Lecciones sobre la historia de la filosofía política. Bogotá: Paidós, 2017.

RESTREPO, C. Tres variaciones alrededor del derecho. Quito: Editorial Casa de la Cultura Ecuatoriana, 1956.

ROUSSEAU, J. J. El contrato social. Buenos Aires: Imprenta Balmes, 1957.

SAGÜÉS, N. P. Manual de derecho constitucional. Buenos Aires: Astrea, 2012.

SCHMITT, C. Teoría de la constitución. Madrid: Alianza Editorial. S.A., 1996.

SIEYÉS, E. ¿Qué es el Tercer Estado? Barcelona: Ediciones Orbis S. A., 1985.

VICIANO, R. El largo camino hacia una constitución europea. En: Revista de Derecho de la Unión Europea, núm. 1 - 2ºmestre 2001.

; MARTÍNEZ DALMAU, R. Los procesos constituyentes latinoamericanos y el nuevo paradigma constitucional. En: IUS Revista del Instituto de Ciencias Jurídicas de Puebla A.C., núm. 25, 2010, pp. 7-29, Instituto de Ciencias Jurídicas de Puebla A. C. Puebla, México.

WEBER, M. Economía y sociedad. México: Fondo de Cultura Económica, 2002. 